\title{
Microwave-Assisted Hydrodistillation of Clove (Syzgium aromaticum) Stem Oil: Optimization and Chemical Constituents Analysis
}

\author{
Haqqyana Haqqyana, Ali Altway, and Mahfud Mahfud \\ Department of Chemical Engineering, Faculty of Industrial Technology and Systems Engineering, \\ Institut Teknologi Sepuluh Nopember, Surabaya 60111, Indonesia
}

\section{* Corresponding author:}

email:mahfud@chem-eng.its.ac.id

Received: March 6, 2021

Accepted: July 7, 2021

DOI: $10.22146 /$ ijc. 64521

\begin{abstract}
One of the extensively prosperous potential aromatic plants is the clove (Syzgium aromaticum). This is owing to all parts of this plant (bud, stem, and leaves) contain a decent amount of essential oils. The current study focuses on the use of microwave-assisted hydrodistillation (MHD) in extracting clove stem essential oils. This study aims to obtain the best possible combination of operating parameters for a high yield of clove stem oil using response surface methodology. The current study adopted a face-centered central composite design to optimize the MHD operational parameters, including the feed-to-solvent ratio, microwave power, and extraction time. The observed data from the experiments were fitted to a reduced quadratic polynomial equation. The three operational parameters were shown to significantly affect the extraction yield of the clove stem oil $(p<0.05)$, yet the statistical significance for the interaction between each parameter was considerably weak. Furthermore, the adjusted $R^{2}$ value measured comparably to the corresponding $R^{2}$ value with the difference below 0.2, implying a high correlation between experimental and model-predicted data. Thus, this result demonstrates the suitability of the model used in the experiment.
\end{abstract}

Keywords: face-centered central composite design; microwave-assisted hydrodistillation; reduced quadratic model; clove oil; Syzgium aromaticum

\section{- INTRODUCTION}

Syzygium aromaticum (S. aromaticum), commonly known as clove, is a kind of aromatic spice that has long been used in various applications such as kretek cigarettes manufacturers, food flavoring, fragrances, and pharmaceuticals. The use of clove plants further developed into the cosmetics industry, and lately, several findings show the potential of using cloves for other purposes, including fish anesthetic [1], natural insecticides [2], and fuel bio-additives [3]. This aromatic plant is commercially harvested in Indonesia, Sri Lanka, India, and some African countries, primarily in Tanzania and Madagascar [4].

Cloves have a pleasant aroma derived from essential oils, which are contained in large enough quantities, whether in its flowers (10-20\%), stems (5-10\%), and leaves (1-4\%) [5]. The essential oil derived from cloves contains a mixture of different compounds, with eugenol, eugenyl acetate, and $\beta$-caryophyllene being the three main active chemicals. The eugenol constituent in cloves and other polyphenolic compounds are known to have antioxidant, antifungal, and antimicrobial activities [67].

Applying an effective extraction method to produce a high-quantity and high-quality yield of essential oil is necessary since the properties and compositions of oils could vary depending on extraction methods. Various approaches have been used for obtaining aromatic oil, such as solvent extraction, hydrodistillation, and steam distillation [8-9]. Aside from the conventional methods, microwave-assisted extraction has attracted extensive response in recent years as it offers many advantages include rapid energy transfer, effective heating, shorter extraction time while preserving a high yield extraction [10]. The microwaveassisted hydrodistillation (MHD) is an advanced 
hydrodistillation method that utilizes water solvent for target component extraction, aided with microwave heating. Reports on the application of the MHD on extracting essential oils from numerous plant materials have also provided promising results [11-12].

The efficiency of the MHD process is influenced by microwave irradiation power and time, properties of the matrix, including its moisture content, and the solventto-feed ratio [13]. When properly and optimally selected, these parameters present maximum process efficiency while retaining the desired components' value. One of the most favorable tools for optimizing experiments' design process is response surface methodology (RSM). The RSM-based analysis allows investigating the possible interaction of the independent factors and their effects on the dependent variable(s). Compared to another classical approach, such as one-factor-at-a-time experimentation, the RSM provides convenience due to its reduced time and lower number of trials. This study was carried out to evaluate the effects of the MHD parameters (microwave power, feed-to-solvent ratio, and extraction time) on the extraction of the essential oil derived from S. aromaticum stem. Furthermore, to investigate the best response surface design for optimizing the S. aromaticum stem oil yield, a central composite with a face-centered design was considered.

\section{- EXPERIMENTAL SECTION}

\section{Materials}

Sun-dried clove stems were collected from local farmland in Malang, East Java. The stems were cut into 2 $\mathrm{cm}$ segments. Distilled water was used as a solvent to extract clove stem oil. While $n$-hexane used was ACS grade (FULLTIME, CAS No. 110-54-3).

\section{Instrumentation}

The microwave hydrodistillation method was handled in a reworked domestic microwave oven (Electrolux EMM2308X). The modification and basic experimental set-up of the microwave extraction apparatus were conducted according to several related studies [1415]. The microwave reactor operates at $2.45 \mathrm{GHz}$ frequency with $800 \mathrm{~W}$ maximum power capability. A Clevenger- type apparatus coupled with a reflux condenser were mounted on top of the microwave oven. The distiller used was a one-neck $1000 \mathrm{~mL}$ round flask. Chemical compounds of the obtained oil were characterized using AGILENT 5973 Inert MS with AGILENT 6980N GC.

\section{Procedure}

\section{Determination of proximate, tannin, and fixed oil}

The proximate analysis of the clove stem was conducted following the Association of Official Agricultural Chemists (AOAC) standard procedures. Moisture content was measured by drying $10 \mathrm{~g}$ of the sample in an oven at $105^{\circ} \mathrm{C}$ to a constant weight. Ash content was determined by burning $2 \mathrm{~g}$ of clove stem on a furnace at $600{ }^{\circ} \mathrm{C}$ for $2 \mathrm{~h}$ [16]. A semi micro-Kjeldahl method was applied to obtain the total crude protein content [17]. Then, tannin and fixed oil were determined using spectrophotometer and Soxhlet method, respectively.

\section{Microwave hydrodistillation (MHD) of clove stem oil}

For each extraction, the clove stem samples were then weighed, following pre-specified plant to water ratios. Distilled water with a fixed volume at $200 \mathrm{~mL}$ was used as a solvent. The starting time of essential oils accumulation was calculated when the distillation of the first oil droplets was observed. Two phases of condensate were obtained, namely the oil phase and the aqueous phase. Due to its difference in density, a significant amount of oil compounds heavier than water would accumulate at the bottom end of the Clevenger trap, while a small fraction of lower compounds would float at the top of the aqueous phase. The oil phase was collected and decanted using a separatory funnel. Both fractions (the lighter and the heavier-than-water oils) were added to obtain the total clove stem oil. The collected clove stem oils were weighed and stored at a cool and dry place. The obtained oil yield of the clove stem was calculated according to Eq. (1) [18].

$\mathrm{y}=\frac{\mathrm{V}}{\mathrm{Z}(1-\mathrm{x})} \times 100 \%$

where $y$ is the clove stem oil yield $(\%, w / w), V$ is the weight of the clove stem oil (g), $\mathrm{Z}$ is the weight of clove stem $(\mathrm{g})$, while $\mathrm{x}$ is the water content (\%). 


\section{FCCD experimental design and analysis of statistic}

An experimental design using response surface methodology (RSM) was performed to explore the influence of process variables and characterize the optimal conditions to extract the essential oil. Central composite design (CCD) was applied to study the effect of independent variables as well as the interactive behavior on the response. The total number of test runs required in CCD is $\mathrm{n}=2^{\mathrm{k}}+2 \mathrm{k}+\mathrm{n}_{\mathrm{C}}$ experiments. Whereas $\mathrm{k}, 2^{\mathrm{k}}, 2 \mathrm{k}$, and $\mathrm{n}_{\mathrm{C}}$ represent the number of factors, factorial point, axial point, and center point runs, respectively.

In this study, the considered independent variables were microwave irradiation power (A: $300-600 \mathrm{~W}$ ), feed/solvent ratio (B: 0.3-0.7 $\mathrm{g} \mathrm{mL}^{-1}$ ), and microwave extraction time (C: $40-120 \mathrm{~min}$ ). The dependent variable chosen as the response was the yield of the clove stem oil $(\mathrm{Y}, \% \mathrm{w} / \mathrm{w})$. Each parameter used in the study was coded at three levels of factor points ( 1 for lower bound, 0 for center point, +1 for upper bound). The coded and actual levels of factors for each experiment were summarized in Table 1. Furthermore, the results of the experimental design are presented in Table 2.
The experimental design for three-factors requires eight $\left(2^{3}\right)$ factorial points, six $(2 \times 3)$ axial points, and center point replication (Table 2). In this study, the center points were measured for five replications, thus concluding the total number of experimental runs at $\mathrm{n}=$ $8+6+5=19$. A total of 19 observations were conducted to fit the second-order polynomial equation as expressed in Eq. (2).

$Y=\beta_{0}+\sum_{j=1}^{k} \beta_{j} X_{j}+\sum_{j=1}^{k} \beta_{j j} X_{j}^{2}+\sum_{i} \sum_{<j=2}^{k} \beta_{i j} X_{i} X_{j}+e_{i}$

whereas $\mathrm{Y}, \beta_{0}, \beta_{\mathrm{i}}, \beta_{\mathrm{i}}, \beta_{\mathrm{ij}}, \mathrm{X}_{\mathrm{i}}, \mathrm{X}_{\mathrm{j}}$, and e represent the response variable, regression coefficient depicting intercept value, linear coefficient, quadratic coefficient, interactive coefficient, coded independent parameters, and experimental error, respectively.

Table 1. Code and levels of desired factors

\begin{tabular}{lccc}
\hline \multirow{2}{*}{\multicolumn{1}{c}{ Factors }} & \multicolumn{3}{c}{ Factor level } \\
\cline { 2 - 4 } & $-1(-\alpha)$ & 0 & $1(+\alpha)$ \\
\hline Microwave power (W) (A) & 300 & 450 & 600 \\
Feed-to-solvent ratio (g mL $\left.\mathrm{g}^{-1}\right)(\mathrm{B})$ & 0.3 & 0.5 & 0.7 \\
Extraction time (min) (C) & 40 & 80 & 120 \\
\hline
\end{tabular}

Table 2. Results of FCCD experiments for clove stem essential oil extraction

\begin{tabular}{ccccccc}
\hline \multirow{2}{*}{ Run } & \multicolumn{3}{c}{ Actual variables } & \multicolumn{3}{c}{ Yield of clove stem oil $(\% \mathrm{w} / \mathrm{w})$} \\
\cline { 2 - 6 } & $\mathrm{A}(\mathrm{W})$ & $\mathrm{B}\left(\mathrm{g} \mathrm{mL}^{-1}\right)$ & $\mathrm{C}(\mathrm{min})$ & Experimental & Predicted & Residue \\
\hline 1 & 450 & 0.5 & 80 & 4.6975 & 4.3509 & 0.3465 \\
2 & 450 & 0.5 & 80 & 4.3259 & 4.3509 & -0.0251 \\
3 & 450 & 0.5 & 80 & 4.4587 & 4.3509 & 0.1078 \\
4 & 450 & 0.7 & 80 & 3.2385 & 3.4422 & -0.2037 \\
5 & 450 & 0.3 & 80 & 5.4683 & 5.4184 & 0.0500 \\
6 & 600 & 0.7 & 40 & 1.9860 & 2.1811 & -0.1951 \\
7 & 300 & 0.3 & 40 & 3.1804 & 3.5213 & -0.3409 \\
8 & 600 & 0.3 & 120 & 6.1023 & 6.1551 & -0.0528 \\
9 & 300 & 0.3 & 120 & 5.4959 & 5.2623 & 0.2336 \\
10 & 300 & 0.7 & 40 & 1.8267 & 1.7354 & 0.0913 \\
11 & 450 & 0.5 & 40 & 3.2348 & 2.9003 & 0.3345 \\
12 & 450 & 0.5 & 80 & 4.1948 & 4.3509 & -0.1561 \\
13 & 300 & 0.5 & 80 & 4.1632 & 4.0753 & 0.0879 \\
14 & 600 & 0.7 & 120 & 4.3185 & 3.9887 & 0.3298 \\
15 & 300 & 0.7 & 120 & 3.7738 & 3.8456 & -0.0718 \\
16 & 450 & 0.5 & 120 & 4.1863 & 4.6746 & -0.4883 \\
17 & 450 & 0.5 & 80 & 4.3852 & 4.3509 & 0.0343 \\
18 & 600 & 0.5 & 80 & 4.5029 & 4.7445 & -0.2417 \\
19 & 600 & 0.3 & 40 & 4.8270 & 4.7168 & 0.1102 \\
\hline & & & & & &
\end{tabular}


All clove stem oil yields collected from the FCCD were analyzed using the Design Expert 12 (State-Ease, Inc., Minneapolis MN, USA; trial version). A statistical method, analysis of variance (ANOVA), was then carried out to calculate and model the optimum conditions for the MHD of clove stem essential oil. The model adequacy was determined by evaluating the coefficient of determination or R-squared value $\left(\mathrm{R}^{2}\right)$, the lack of fit, adjusted determination coefficient $\left(\mathrm{R}^{2}{ }_{\mathrm{Adj}}\right)$, and adequate precision. This study preferred a statistical significance at $p$-value $<0.05$.

\section{Gas chromatography-mass spectrometry (GC-MS) analysis of chemical component}

In determining the quality of the clove stem essential oil obtained using the MHD method, it is necessary to identify the chemical properties of the essential oil. The analysis was performed by identifying the composition of clove stem essential oils using GC-MS (AGILENT 6980N chromatography gas coupled with AGILENT 5973 inert mass spectrometry). The sample was injected at $250{ }^{\circ} \mathrm{C}$ inlet temperature with a split ratio of 1:50. The flow rate inside the GC column was held constant at $1 \mathrm{~mL} \mathrm{~min}{ }^{-1}$. Wiley's mass spectral data library (version 7.0) is used to identify the chromatographic peaks. The peak percentage was calculated using the total ion chromatogram (TIC) peak area [19].

\section{- RESULTS AND DISCUSSION}

\section{Proximate, Tannin, and Fixed Oil Determination of the Clove Stem}

It was found that the moisture content of the clove stem was $15.35 \%$. The analysis results show that the clove stem contained a low amount of crude protein (4.95\%). It is slightly lower than the crude protein amount from the clove stem measured by Tharpe [20]. It was reported that a relatively small amount of $5.8-6.0 \%$ protein was found on the clove stem. Meanwhile, the ash content of $8.94 \%$ found in this study is comparable to the previous study (6.9-9.0\%). The fixed oil from the clove stem was extracted with $n$-hexane using the Soxhlet apparatus. We obtained a considerable amount of fixed oil and resin (7.25\%), higher than Tharpe's (3.5-4.0\%) [20]. Furthermore, a lower tannin content of $6.75 \%$ compared to the study reported by Tharpe (with approximately $10 \%$ of tannin) [20] was measured.

\section{Model Fitting for Clove Stem Oil MHD}

In the current study, the MHD parameters, including microwave irradiation power, feed-to-solvent ratio, and microwave extraction time, were optimized using FCCD to obtain the maximum value of clove stem essential oil yield. The experimental values for extraction yield $(\% \mathrm{w} / \mathrm{w})$ as a response variable under different combinations were presented in Table 2 . The clove stem oil yield varied broadly as a function of process parameters, ranging from $1.826-6.102 \% \mathrm{w} / \mathrm{w}$.

The least-squares regression was applied to study the relationship of the response with the three regression variables. Tables 3 and 4 present the model fitting procedure generated from the Design Expert statistical software. The obtained experimental data were fitted to a series of regression models, including linear, firstorder interaction (2FI), fully quadratic, and cubic models. The polynomial model that is used to approximate the response surface and optimization must not be an aliased model. Furthermore, the selected model must also be the highest-order polynomial with significant additional terms [21]. Due to the central composite design's inability to thoroughly estimate the cubic model parameters, labeled as aliased, thus the model is excluded from further consideration. Table 3 indicates that the fully quadratic model is appropriate because its lack of fit $p$-value displayed a favorable insignificant statistical trend with 0.0784 ( $>0.05)$, compared to a linear model. An insignificant lack of fit is recommended. The difference between the predicted $\mathrm{R}$-squared of the linear model and its adjusted Rsquared is less than 0.2 , which depicted a considerable agreement. However, further summarized in Table 3 and the ANOVA results (Table 5, as discussed in the following sub-chapter), the quadratic terms have an almost but not quite significant effect on the response; thus, omitting these factors could negatively affect the data analysis. Furthermore, higher-order polynomial models could explain variations in error terms for the corresponding low-order models [22]. Therefore, we indicated this model for provisional preference. 
Table 3. Summary of the sequential model sum of squares (type I) and lack of fit tests from respective models

\begin{tabular}{|c|c|c|c|c|c|}
\hline Source & $\mathrm{SS}^{\mathrm{a}}$ & $\mathrm{DF}^{\mathrm{b}}$ & $\mathrm{MS}^{\mathrm{c}}$ & $F$-value & $p$-Value ${ }^{\mathrm{d}}$ \\
\hline \multicolumn{6}{|c|}{ Summary of the sequential model sum of squares (type I) } \\
\hline Mean vs Total & 323.23 & 1 & 323.23 & & \\
\hline Linear vs Mean & 18.73 & 3 & 6.24 & 36.80 & $<0.0001$ \\
\hline 2FI vs Linear & 0.4129 & 3 & 0.1376 & 0.7748 & 0.5302 \\
\hline Quadratic vs 2FI & 1.17 & 3 & 0.3898 & 3.64 & 0.0573 \\
\hline Cubic vs Quadratic & 0.7680 & 4 & 0.1920 & 4.94 & 0.0549 \\
\hline Residual & 0.1944 & 5 & 0.0389 & & \\
\hline Total & 344.50 & 19 & 18.13 & & \\
\hline \multicolumn{6}{|c|}{ Lack of fit tests } \\
\hline Linear & 2.41 & 11 & 0.2187 & 6.30 & 0.0452 \\
\hline $2 \mathrm{FI}$ & 1.99 & 8 & 0.2491 & 7.17 & 0.0372 \\
\hline Quadratic & 0.8235 & 5 & 0.1647 & 4.74 & 0.0784 \\
\hline Cubic (aliased) & 0.0554 & 1 & 0.0554 & 1.60 & 0.2751 \\
\hline Pure Error & 0.1390 & 4 & 0.0347 & & \\
\hline \multicolumn{6}{|l|}{ a Sum of squares } \\
\hline \multicolumn{6}{|l|}{${ }^{b}$ Degree of freedom } \\
\hline $\begin{array}{l}{ }^{c} \text { Mean sum of squares } \\
\text { d } p \text { values }<0.05 \text {; signifi }\end{array}$ & & & & & \\
\hline
\end{tabular}

Table 4. Summary of respective model statistics

\begin{tabular}{lccccr}
\hline Source & Std. Dev. & $\mathrm{R}^{2}$ & Adjusted $^{2}$ & Predicted $\mathrm{R}^{2}$ & PRESS \\
\hline Linear & 0.4119 & 0.8804 & 0.8565 & 0.7918 & 4.43 \\
2FI & 0.4215 & 0.8998 & 0.8497 & 0.5082 & 10.46 \\
Quadratic & 0.3270 & 0.9548 & 0.9095 & 0.5107 & 10.41 \\
Cubic & 0.1972 & 0.9909 & 0.9671 & -2.3965 & 72.26 \\
\hline
\end{tabular}

Development of Regression Model and ANOVA

\section{Evaluation}

A final quadratic polynomial equation regarding the actual factors was obtained by applying the multiple regression analysis, as shown in Eq. (3).

$$
\begin{aligned}
\mathrm{y}= & 1.2969+0.0042{ }^{\star} \mathrm{A}-4.8478^{\star} \mathrm{B}+0.0794^{\star} \mathrm{C} \\
& -0.0065^{\star} \mathrm{AB}-1.3644 \mathrm{e}^{-05} \mathrm{AC}+0.0108^{\star} \mathrm{BC} \\
& +2.5194 \mathrm{e}^{-06 \star} \mathrm{A}^{2}+1.9261^{\star} \mathrm{B}^{2}-0.0004{ }^{\star} \mathrm{C}^{2}
\end{aligned}
$$

where $\mathrm{y}$ is the extraction yield of clove stem essential oil $(\% \mathrm{w} / \mathrm{w}), \mathrm{A}$ is microwave power $(\mathrm{W}), \mathrm{B}$ is the feed-tosolvent ratio $\left(\mathrm{g} \mathrm{mL}^{-1}\right)$, and $\mathrm{C}$ is the time of extraction (min).

Following the developed equation, interpretation of each factor's effects' on the response regarding the sign and magnitude of the coefficients can be concluded [23]. Coefficients with a plus sign favor optimization thus could promote an increase in the response. Meanwhile, the minus sign indicates a contrary notion on the response, so that an increase in values of the coefficients will decrease the response values. The quadratic model implied that the linear coefficients for microwave power (A) and extraction time (C), the quadratic terms $\mathrm{A}^{2}$ and $\mathrm{B}^{2}$, and the interaction variables $\mathrm{BC}$, established positive effects. In contrast, the linear term $\mathrm{B}$, the interactive term $\mathrm{AB}$, and the quadratic term $\mathrm{C}^{2}$ displayed negative significances on the extraction yield.

The observed data were analyzed using ANOVA, and the results were summarized in Table 5. Evaluation of significance and suitability of the predictive quadratic model was considered by their $p$-value $(p<0.05)$ and Fisher $F$-value. As shown in Table 5 , linear terms of feedto-solvent ratio (B) and extraction time $(\mathrm{C})$ had the most considerable effects $(p<0.0001)$ on the clove stem oil yield. The linear term of microwave power $(\mathrm{A})$ and the quadratic term of the extraction time $\left(\mathrm{C}^{2}\right)$ were also significant but less substantial. Otherwise, all the 
interaction effects of the model $(\mathrm{AB}, \mathrm{AC}, \mathrm{BC})$ and the quadratic terms of microwave power $\left(\mathrm{A}^{2}\right)$ and the ratio of feed-to-solvent $\left(\mathrm{B}^{2}\right)$ were insignificant $(p>0.05)$. Hence, the result suggests that the yield of essential oil from the clove stem is highly dependent on the change of feed-tosolvent ratio and the extraction time. It was also noted that the quality of the quadratic model exhibits a good fit with an $F$-value of 21.11 and a $p$-value $<0.0001$. However, the estimated $p$-value for lack of fit was approaching though not reaching the preset significance level ( $p 0.0784$ $>0.05$ ). The lack of fit $\mathrm{F}$ value 4.74 describes a $7.84 \%$ chance that the large value could occur due to noise. The relatively low probability $(<10 \%)$ is concerning. Insignificant model terms could be excluded in order to simplify and improve model sufficiency. The model equation for the MHD of the clove stem oil obtained after eliminating the non-significant effects is expressed in Eq. (4).

$$
\begin{aligned}
y= & 2.15692+0.002198^{*} A-4.96527 * B+0.070905^{\star} C \\
& -0.000305 C^{2}
\end{aligned}
$$

According to the ANOVA results for the reduced quadratic model summarized in Table 5 , the estimated $p$-value for lack of fit is not significant ( $p 0.1109>0.05)$. This finding indicates that the model equation was adequate for predicting the relevant response. Thus, the variation in the responses could be explained by the model [23]. The values of $R$-squared $\left(R^{2}\right)$, adjusted $R$ squared $\left(\mathrm{R}_{\text {adj }}^{2}\right)$, coefficient of variation $(\mathrm{CV} \%)$, and adequate precision were also calculated to determine the goodness of the model fit to the experimental data. In this study, the $\mathrm{R}^{2}$ and $\mathrm{R}_{\text {adj }}^{2}$ values were 0.9335 and 0.9145 , respectively, indicating a relatively high correlation of the model developed through experimental data [24]. Moreover, the predicted $\mathrm{R}^{2}$ of 0.8530 is statistically acceptable with the adjusted $\mathrm{R}^{2}$ of 0.9145 . The high value of predicted $\mathrm{R}^{2}$ signified the model's capability to provide

\begin{tabular}{|c|c|c|c|c|c|c|c|}
\hline DoE Model & Source & DF & SS & MS & $F$-value & $p$-Value & \\
\hline \multirow{14}{*}{$\begin{array}{l}\text { FCCD - } \\
\text { fully } \\
\text { quadratic }\end{array}$} & Model & 9 & 20.31 & 2.26 & 21.11 & $<0.0001$ & \\
\hline & A-Microwave power & 1 & 1.09 & 1.09 & 10.16 & 0.0110 & \\
\hline & B-Feed/solvent ratio & 1 & 9.86 & 9.86 & 92.22 & $<0.0001$ & \\
\hline & C-Extraction time & 1 & 7.78 & 7.78 & 72.78 & $<0.0001$ & \\
\hline & $\mathrm{AB}$ & 1 & 0.3000 & 0.3000 & 2.81 & 0.1283 & ${ }^{\mathrm{e}} \mathrm{ns}$ \\
\hline & $\mathrm{AC}$ & 1 & 0.0536 & 0.0536 & 0.5013 & 0.4968 & ${ }^{\mathrm{e}} \mathrm{ns}$ \\
\hline & BC & 1 & 0.0593 & 0.0593 & 0.5548 & 0.4754 & ${ }^{\mathrm{e}} \mathrm{ns}$ \\
\hline & $\mathrm{A}^{2}$ & 1 & 0.0088 & 0.0088 & 0.0821 & 0.7809 & ${ }^{\mathrm{e}} \mathrm{ns}$ \\
\hline & $\mathrm{B}^{2}$ & 1 & 0.0162 & 0.0162 & 0.1517 & 0.7060 & ${ }^{\mathrm{e}} \mathrm{ns}$ \\
\hline & $\mathrm{C}^{2}$ & 1 & 0.8746 & 0.8746 & 8.18 & 0.0188 & \\
\hline & Residual & 9 & 0.9624 & 0.1069 & & & \\
\hline & Lack of fit & 5 & 0.8235 & 0.1647 & 4.74 & 0.0784 & ${ }^{\mathrm{e}} \mathrm{ns}$ \\
\hline & Pure error & 4 & 0.1390 & 0.0347 & & & \\
\hline & Total & 18 & 21.28 & & & & \\
\hline \multirow{9}{*}{$\begin{array}{l}\text { FCCD - } \\
\text { reduced } \\
\text { quadratic }\end{array}$} & Model & 4 & 19.86 & 4.97 & 49.15 & $<0.0001$ & \\
\hline & A-Microwave power & 1 & 1.09 & 1.09 & 10.76 & 0.0055 & \\
\hline & B-Feed/solvent ratio & 1 & 9.86 & 9.86 & 97.62 & $<0.0001$ & \\
\hline & C-Extraction time & 1 & 7.78 & 7.78 & 77.04 & $<0.0001$ & \\
\hline & $\mathrm{C}^{2}$ & 1 & 1.13 & 1.13 & 11.19 & 0.0048 & \\
\hline & Residual & 14 & 1.41 & 0.1010 & & & \\
\hline & Lack of fit & 10 & 1.28 & 0.1275 & 3.67 & 0.1109 & ${ }^{\mathrm{e}} \mathrm{ns}$ \\
\hline & Pure error & 4 & 0.1390 & 0.0347 & & & \\
\hline & Total & 18 & 21.28 & & & & \\
\hline
\end{tabular}

Table 5. Summary of ANOVA test for the developed fully-quadratic and reduced quadratic model

${ }^{\mathrm{e}}$ ns: not significant 
valid predictions on new experimentations. The coefficient of variation (CV\%) value of $7.71 \%$ indicated good precision and reliability of the experimental results. A value of the coefficient of variation below 10 is desired, implying that the model is reproducible [25]. In addition, an adequate precision level that is greater than 4 is preferred. The adequate precision resulted in this study was 27.0460, which defines as an adequate signal and signifies good fitness of the developed model. Thus, the reduced quadratic model could be applied to optimize the MHD extraction process.

\section{Diagnostic of Reduced Second-Order Model Adequacy}

Evidence on the relationship and model sufficiency is acquirable by plotting essential oil yield predicted and experimental values on a fitted-line plot. Fig. 1(a) displayed the normal probability plot of residuals derived from the reduced quadratic model for the yield of clove stem oil. The plot indicates that the residuals follow the straight line, thus reflected normal distribution. A small residual value is desirable since it implied that the model prediction is accurate [23]. Moreover, from Fig. 1(b), it was observed that the experimental values were adjacent to the straight line of the predicted yields. Appropriate prediction on the yield of the clove stem oil was apparent in the developed model, as revealed by the plot. This result thus corroborated the high calculated $\mathrm{R}^{2}$ value $(0.9335)$.
Fig. 2 demonstrated the relationship between externally studentized residuals and run number of (a) reduced quadratic and (b) fully quadratic models. The graph was plotted to evaluate the experimental data and identify the sufficient fit of the developed models [24]. The residuals between the observed data values and the model-predicted responses fall within the acceptable range of -4 to +4 shown in Fig. 2(a). Therefore, by applying the reduced quadratic model equation, it can be concluded that no outliers were identified among the actual data set obtained from the experiment. In contrast, there was one observation detected that was likely to be an outlier in Fig. 2(b).

\section{Analysis of Response Surfaces and Contour Plots}

To better understand the behavior of the developed reduced quadratic model, analysis of response surface and contour plots for each model were presented and discussed. Three-dimensional (3D) response surface and two-dimensional (2D) contour plots of the regression models were applied to represent the interrelation between independent and response variables (Fig. 3-4). The results demonstrated the effects of each independent variable (extraction time, irradiation power, the feed-to-solvent ratio) and their interactions on the oil yield of clove stem. In general, the extraction yield obtained in this study increases as the microwave power and extraction time increase.
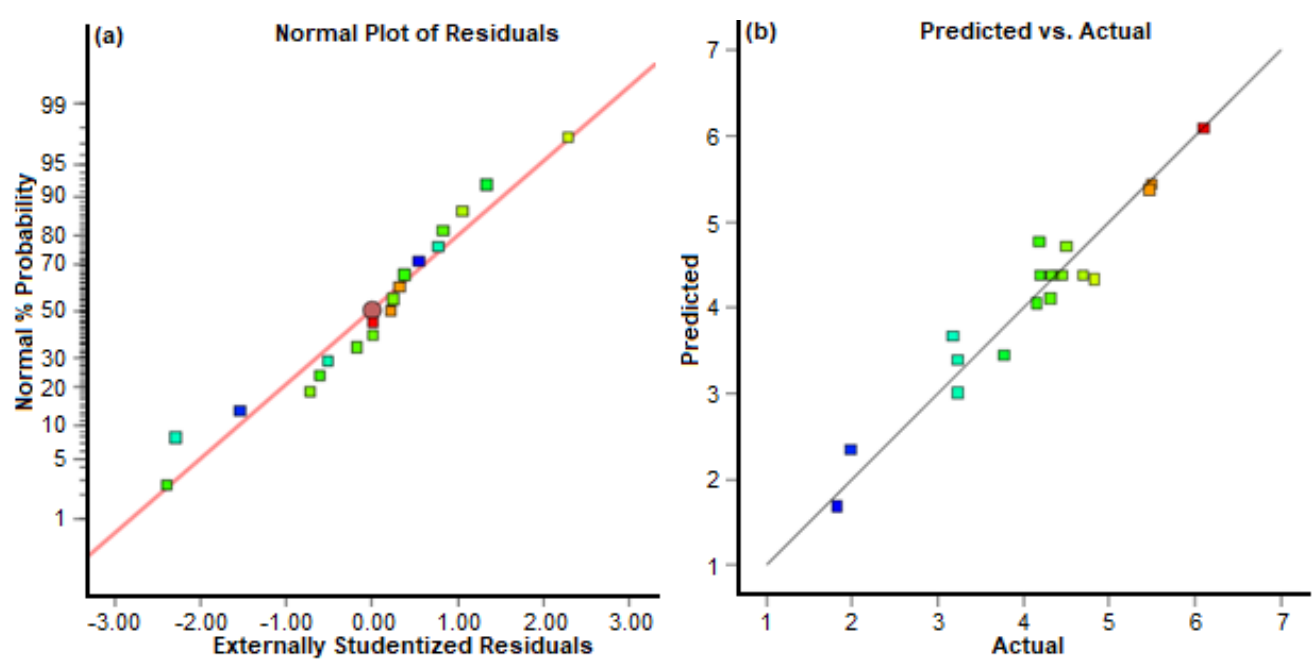

Fig 1. Plots of reduced quadratic model: (a) Normal \% Probability, and (b) Predicted vs. Actual 

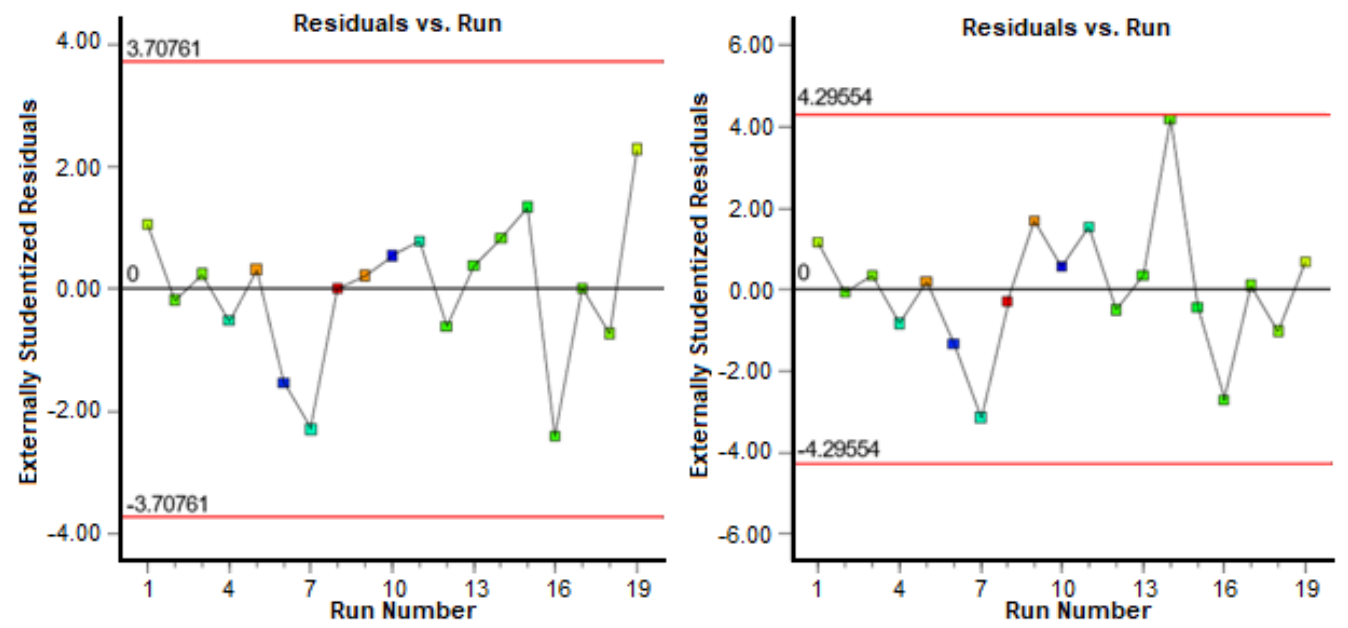

Fig 2. Externally studentized residuals vs. run number plots of (a) Reduced quadratic, and (b) Fully quadratic models
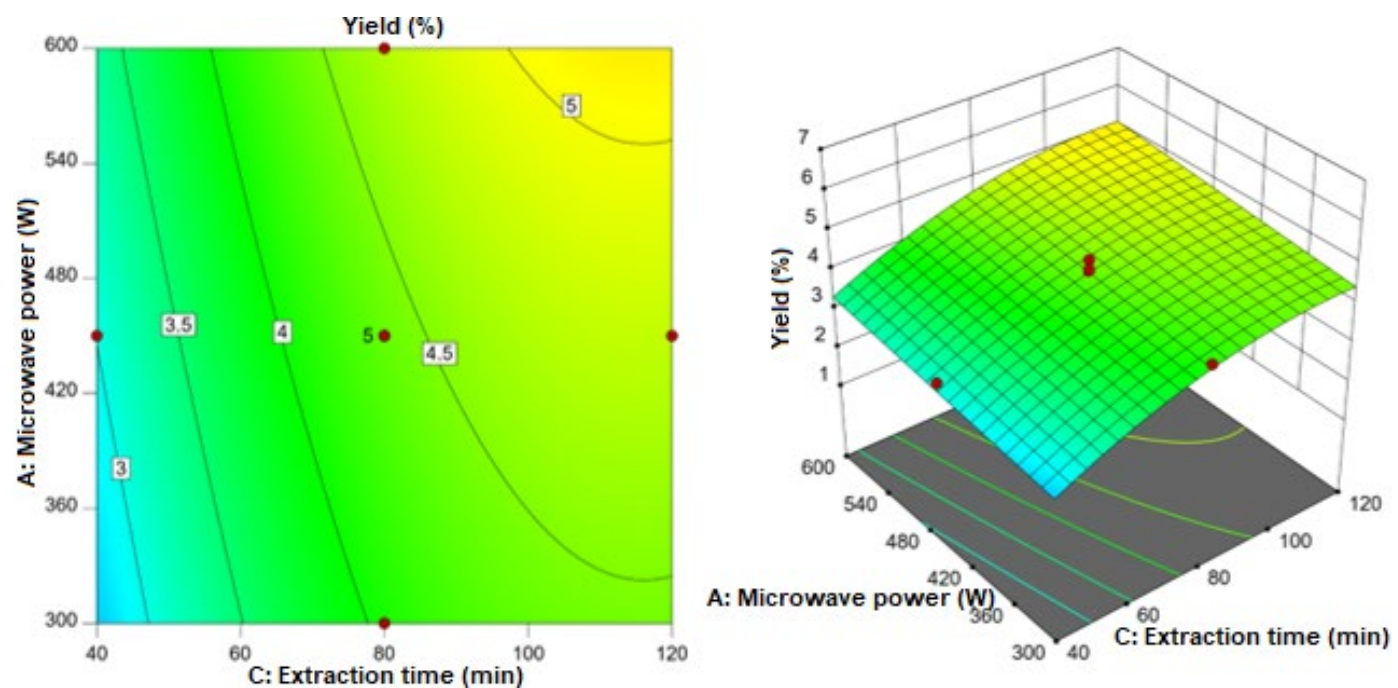

Fig 3. The $2 \mathrm{D}$ contour plot (left) and $3 \mathrm{D}$ response surface (right) of the reduced quadratic model displaying the effect of parameters (A) the microwave power and (C) the extraction time on the clove stem oil yield

Fig. 3 displays the mutual effects of microwave irradiation power and extraction time at a fixed $0.5 \mathrm{~g} \mathrm{~mL}^{-1}$ feed-to-solvent ratio. The increase of both microwave power $(300-600 \mathrm{~W})$ and extraction time (40-120 $\mathrm{min})$ significantly improved the yield of clove stem oil, as portrayed in Fig. 3. Higher microwave power level promotes greater energy received by the solvent and plant matrix, which in turn causes the yield of clove stem essential oil to rise. The higher yield obtained follows the rapid increase in temperature due to the increasing amount of irradiation power emitted. An increase in solvent power is encouraged due to reduced solvent viscosity and surface tension between sample matrix and solvent. This behavior facilitates enhanced wetting of sample and solvent penetration, resulting in improved solubility and diffusion rates of solutes [26]. The result is similar to Singh et al. [27], who studied lemongrass oil extraction by microwave heating and showed that a high microwave power level could provide a higher yield and accelerate the extraction time. However, other studies have also suggested that further increasing microwave power up to a certain level causes degradation of thermolabile substances and volatiles, thus negatively affected the oil yields [28-29].

Nevertheless, the effect of irradiation power on the extracted clove oil yield at a low feed/solvent ratio was greater than the effect at a high feed/solvent ratio (Fig. 4). Fig. 4 describes the interactive effect of microwave 
power and feed matrices to water ratio for a constant extraction time of $80 \mathrm{~min}$. It can be implied that the microwave power and feed/solvent ratio have antagonistic effects on the yield of clove stem oil. The yield of oil from clove stem increased with decreasing feed/solvent ratio from 0.7 to $0.3 \mathrm{~g} \mathrm{~mL}^{-1}$. Increasing the mass of raw materials reduces the surface area of the material that can be penetrated by the solvent, thereby reducing the solvent's ability to extract and isolate the essential oil out of the plant matrices [30-31].

Moreover, increased microwave power encourages the extraction rate of the essential oil, which improves the oil yield obtained. As depicted in Fig. 4, the highest oil yield was obtained at a higher irradiation power range from 470 up to $600 \mathrm{~W}$ and a lower range of feed/solvent ratios $\left(0.3-0.4 \mathrm{~g} \mathrm{~mL}^{-1}\right)$. However, it was also observed that a higher feed/solvent ratio $\left(0.6-0.7 \mathrm{~g} \mathrm{~mL}^{-1}\right)$ could only provide a slight amount of oil yield at any level of irradiation power. At high solid loading (lower ratio of solvent), the changes in microwave power showed no significant effect on the extract yield. This result might be due to the decrease of the incident microwaves per particle with the increase of solid loading in the vessel at a particular power level, thus reduced the dielectric heating effect [32]. This finding is comparable with phenolic

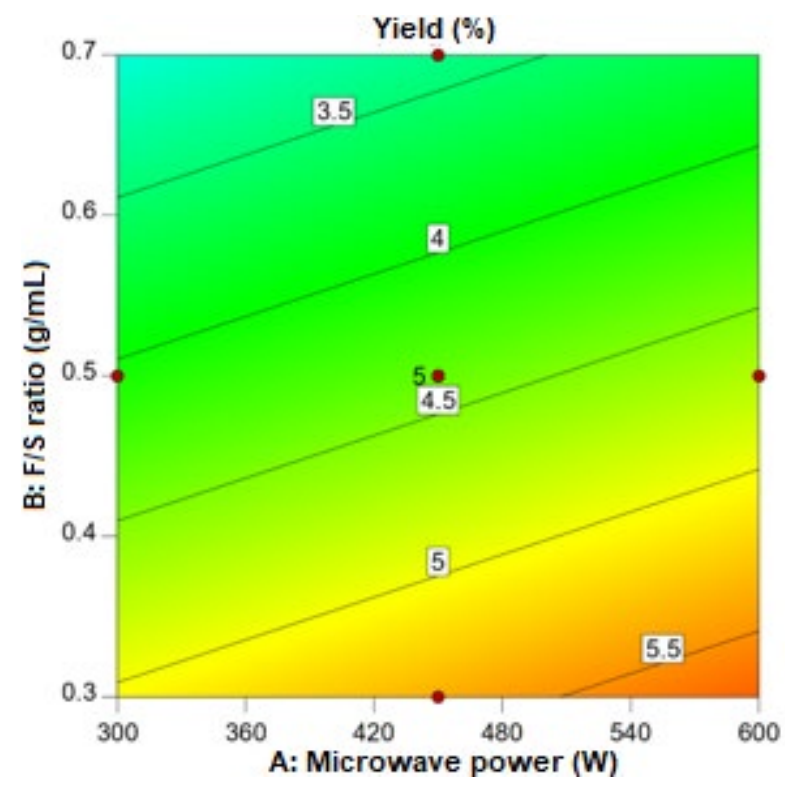

compounds extraction from $V$. cinerea leaves under microwave radiation [33].

\section{Optimization of Extraction Conditions of Essential Oil from Clove Stem}

According to the reduced second-order model expressed in Eq. (4), the optimal experimental conditions to improve the clove stem essential oil yield were the level of microwave power $599.883 \mathrm{~W}$, feed/solvent ratio $0.3 \mathrm{~g} \mathrm{~mL}^{-1}$, and microwave extraction time $116.656 \mathrm{~min}$. Under these conditions, the maximum yield of clove stem oil $(6.102 \%, w / w)$ was obtained. Experiments were conducted to validate the optimum parameter conditions. Adjustment on some parameters, such as microwave power and extraction time, was made to facilitate the observation. The microwave power value used in this experiment was $600 \mathrm{~W}$. Comparison of the optimized parameter derived from the reduced quadratic model and fully quadratic model was presented in Table 6 . The results showed that the experimental yield obtained was approaching the predicted value of the reduced quadratic model. Thus, it can be implied that the reduced second-order model was provisionally adequate to describe the effects of corresponding variables on the yield of clove stem oil obtained from MHD.

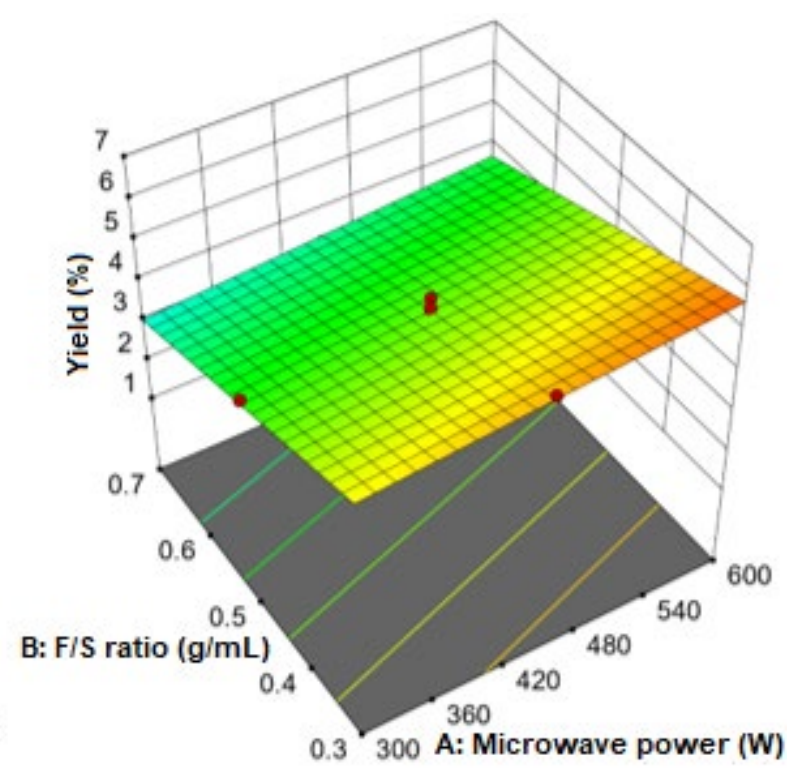

Fig 4. The $2 \mathrm{D}$ contour plot (left) and $3 \mathrm{D}$ response surface (right) of the reduced quadratic model displaying of the microwave power (A) and feed/solvent ratio (B) on the clove stem oil extraction yield 
Table 6. Comparison of validation experiments

\begin{tabular}{|c|c|c|c|c|c|}
\hline Model & $\begin{array}{l}\text { Optimized parameter } \\
\text { (predicted value) }\end{array}$ & $\begin{array}{l}\text { Optimized parameter } \\
\text { (experimental value) }\end{array}$ & $\begin{array}{l}\text { Predicted yield } \\
(\%, \mathrm{w} / \mathrm{w})\end{array}$ & $\begin{array}{c}\text { Experimental yield } \\
(\%, \mathrm{w} / \mathrm{w})\end{array}$ & $\begin{array}{l}\text { Residuals } \\
(\%, \mathrm{w} / \mathrm{w})\end{array}$ \\
\hline Fully quadratic & $\begin{array}{l}597.62 \mathrm{~W} ; 0.304 \mathrm{~g} \mathrm{~mL}^{-1} \text {; } \\
104.958 \mathrm{~min}\end{array}$ & $\begin{array}{l}600 \mathrm{~W} ; 0.304 \mathrm{~g} \mathrm{~mL}^{-1} ; \\
105 \mathrm{~min}\end{array}$ & 6.194 & 4.997 & 1.197 \\
\hline Reduced quadratic & $\begin{array}{l}599.883 \mathrm{~W} ; 0.3 \mathrm{~g} \mathrm{~mL}^{-1} \text {; } \\
116.656 \mathrm{~min}\end{array}$ & $\begin{array}{l}600 \mathrm{~W} ; 0.3 \mathrm{~g} \mathrm{~mL} \mathrm{~m}^{-1} \\
116 \mathrm{~min} 39 \mathrm{sec}\end{array}$ & 6.102 & 5.585 & 0.517 \\
\hline
\end{tabular}

\section{The Chemical Constituents of The Clove Stem Essential Oil}

The chemical composition of the clove stem oil obtained by MHD under the operating conditions; $600 \mathrm{~W}$, feed/solvent ratio $0.5 \mathrm{~g} \mathrm{~mL}^{-1}$, extraction time $120 \mathrm{~min}$, was identified using GC-MS (Table 7). A total of 9 constituents of the clove stem oil yield obtained from this study were identified by GC-MS analysis, i.e. methyl salicylate, chavicol, eugenol, eugenyl acetate, methyl eugenol, caryophyllene oxide, and three unknown compounds. The major chemical substance was eugenol, which accounted for $95.91 \%$ of the total essential oil yield derived from clove stem. Compared with those several studies reported on the extraction of clove stem using conventional methods such as distillation [34] and steam distillation [35], eugenol was also present as the main chemical constituent.

Contrary to other reports that applied conventionalbased methods [7,20,35-36], no $\beta$-caryophyllene (BCP) was observed in this study. In a previous study evaluating the effect of microwave extraction on the chemical composition of clove bud oil, a significant decrease in BCP content was described by Kennouche et al. [37]. It was reported that reduction in $\mathrm{BCP}$ was observed on the clove oil extracted using MHD (17.2\%), but higher BCP content was attained using conventional hydrodistillation. No significant changes to caryophyllene oxide - a secondary oxidation product of $\mathrm{BCP}$ - were reported, despite a slight increase of other caryophyllene derivatives and isomers was identified upon irradiation. It could be implied that the evaporation of some of the more volatile terpenes (e.g., BCP) was slightly accelerated by microwave irradiation. The formation of other BCP derivatives could also suggest the effect of irradiation in BCP degradation.

Interestingly, another study conducted by Golmakani et al. [38] on clove bud oil extraction using conventional
Table 7. The clove stem oil composition obtained from this study

\begin{tabular}{llc}
\hline RT $(\min )$ & Constituents & \% Normalized area \\
\hline 8.36 & Methyl salicylate & 0.34 \\
10.70 & Chavicol & 0.13 \\
$11.68 ; 11.91 ; 11.96$ & Eugenol & 95.91 \\
12.34 & Methyl Eugenol & 0.61 \\
13.47 & Eugenyl acetate & 0.93 \\
13.94 & Caryophyllene oxide & 1.40 \\
14.19 & Unknown & 0.14 \\
18.21 & Unknown & 0.18 \\
28.25 & Unknown & 0.37 \\
\hline
\end{tabular}

and microwave-assisted hydrodistillation reported different results. A significant increase in caryophyllene and humulene - a caryophyllene isomer - and a slight decrease in caryophyllene oxide were observed upon irradiation. Golmakani et al. [38] also disclosed in their study that reduction in eugenol, caryophyllene, and caryophyllene oxide was observed on the steam distillation product, compared to conventional and MHD methods. It was reported that a lower extraction rate was observed due to a longer duration required for conventional methods could affect the extracted oil.

While the current study indicated the presence of caryophyllene oxide (1.40\%) and no presence of $\mathrm{BCP}$ and/or other BCP derivatives was identified, it is difficult to justify whether irradiation solely affected the oil compositions. Nevertheless, irradiation would probably affect the loss of BCP observed in the current study, owing to the volatileness and heat-sensitive characteristic of the terpene [39-40]. Other factors such as irrigation [41], crushing [42], drying process and storage [43], as well as the characteristics of plant matrix that is highly influenced by geographical and ecological situation [44], has also been reported to significantly influence the chemical constituents of essential oils. 


\section{- CONCLUSION}

An experimental design based on the FCCD was successfully implemented to optimize the MHD of essential oil yield derived from the clove stem. The reduced quadratic model was developed to optimize the operating conditions of the MHD extraction of clove stem oil. The coefficient determination $\left(\mathrm{R}^{2}\right)$ and adjusted $\mathrm{R}^{2}$ $\left(\mathrm{R}^{2}{ }_{\mathrm{adj}}\right)$ of the developed reduced quadratic model were 0.9335 and 0.9145 , respectively, showing a relatively high degree of precision between the model-predicted and experimental values. It was also found that the operating parameters, particularly microwave irradiation power and extraction time, had the most significant impact on the extraction yield. Furthermore, the MHD method is allusive as a conscientious technique for extracting essential oils derived from clove stem for numerous applications in industry, owing to its significant extraction efficiency.

\section{- ACKNOWLEDGMENTS}

This work was supported by the Directorate General of the Science and Technology Resource and Higher Education through the Pendidikan Magister Menuju Doktor untuk Sarjana Unggul (PMDSU) Scholarship Batch IV scheme. We would like to thank Verycha F.W. Tania, Ayu M. Suyadi, and Heri S. Kusuma for their technical support on this project. We also appreciate the assistance given by the technical staffs of ULP Faculty of Pharmacy and Nutrition Lab Faculty of Public Health Universitas Airlangga.

\section{- REFERENCES}

[1] Aydın, B., and Barbas, L.A.L., 2020, Sedative and anesthetic properties of essential oils and their active compounds in fish: A review, Aquaculture, 520, 734999.

[2] Tian, B.L., Liu, Q.Z., Liu, Z.L., Li, P., and Wang, J.W., 2015, Insecticidal potential of clove essential oil and its constituents on Cacopsylla chinensis (Hemiptera: Psyllidae) in laboratory and field, J. Econ. Entomol., 108 (3), 957-961.

[3] Jeyakumar, N., and Narayanasamy, B., 2019, Clove as antioxidant additive in diesel-biodiesel fuel blends in diesel engines, Int. J. Green Energy, 16 (4), 284-292.

[4] Kuete, V., 2017, Medicinal Spices and Vegetables from Africa Therapeutic Potential Against Metabolic, Inflammatory, Infectious and Systemic Diseases, Academic Press, Amsterdam.

[5] Nurdjannah, N., 2016, Diversifikasi penggunaan cengkeh, Perspektif, 3 (2), 61-70.

[6] Hu, Q., Zhou, M., and Wei, S., 2018, Progress on the antimicrobial activity research of clove oil and eugenol in the food antisepsis field, J. Food Sci., 83 (6), 1476-1483.

[7] Kaur, K., Kaushal, S., and Rani, R., 2019, Chemical composition, antioxidant and antifungal potential of clove (Syzygium aromaticum) essential oil, its major compound and its derivatives, J. Essent. OilBear. Plants, 22 (5), 1195-1217.

[8] Guan, W., Li, S., Yan, R., Tang, S., and Quan, C., 2007, Comparison of essential oils of clove buds extracted with supercritical carbon dioxide and other three traditional extraction methods, Food Chem., 101 (4), 1558-1564.

[9] Rastuti, U., Diastuti, H., Chasani, M., Purwati, and Hidayatullah, R., 2020, Chemical composition and antioxidant activities of citronella essential oil Cymbopogon nardus (L.) Rendle fractions, AIP Conf. Proc., 2237, 020035.

[10] Golmakani, M.T., and Moayyedi, M., 2016, Comparison of microwave-assisted hydrodistillation and solvent-less microwave extraction of essential oil from dry and fresh Citruslimon (Eureka variety) peel, J. Essent. Oil Res., 28 (4), 272-282.

[11] Kusuma, H.S., Putri, D.K., Triesty, I., and Mahfud, M., 2019, Comparison of microwave hydrodistillation and solvent-free microwave extraction for extraction of agarwood oil, Chiang Mai J. Sci., 46 (4), 741-755.

[12] Marković, M.S., Milojević, S., Bošković-Vragolović, N.M., Pavićević, V.P., Babincev, L., and Veljković, V.B., 2019, A new kinetic model for the common juniper essential oil extraction by microwave hydrodistillation, Chin. J. Chem. Eng., 27 (3), 605-612.

[13] Veggi, P.C., Martinez, J., and Meireles, M.A.A., 2013, "Fundamentals of Microwave Extraction" in 
Microwave-assisted Extraction for Bioactive Compounds, Eds. Chemat, F., and Cravotto, G., Springer, US, 15-52.

[14] Abedi, A.S., Rismanchi, M., Shahdoostkhany, M., Mohammadi, A., and Mortazavian, A.M., 2017, Microwave-assisted extraction of Nigella sativa L. essential oil and evaluation of its antioxidant activity, J. Food Sci. Technol., 54 (12), 3779-3790.

[15] Ma'sum, Z., Kusuma, H.S., Altway, A., and Mahfud, M., 2019, On the effect of the ratio of the distiler volume and that of the microwave cavity on the extraction of Cymbopogon nardus dried leaves by microwave hydro-distillation, J. Chem. Technol. Metall., 54 (4), 778-786.

[16] AOAC, 2005, Official Methods of Analysis of AOAC International, $18^{\text {th }}$ Ed., AOAC International, Gaithersburg, MD, USA, Official Method 942.05.

[17] AOAC, 2005, Official Methods of Analysis of AOAC International, $18^{\text {th }}$ Ed., AOAC International, Gaithersburg, MD, USA, Official Method 978.04.

[18] Kusuma, H.S., Syahputra, M.E., Parasandi, D., Altway, A., and Mahfud, M., 2017, Optimization of microwave hydro-distillation of dried patchouli leaves by response surface methodology, Rasayan $\mathrm{J}$. Chem., 10 (3), 861-865.

[19] Kiliç, M., Pütün, A.E., Uzun, B.B., and Pütün, E., 2014, Converting of oil shale and biomass into liquid hydrocarbons via pyrolysis, Energy Convers. Manage., 78, 461-467.

[20] Ketaren, S., 1985, Pengantar Teknologi Minyak Atsiri, Balai Pustaka, Jakarta.

[21] Myers, R.H., Montgomery, D.C., and AndersonCook, C.M., 2016, Response Surface Methodology: Process and Product Optimization Using Designed Experiments, $4^{\text {th }}$ Ed., Wiley, Hoboken, New Jersey.

[22] Anderson, M.J., and Whitcomb, P.J., 2016, RSM Simplified: Optimizing Processes Using Response Surface Methods for Design of Experiments, $2^{\text {nd }}$ Ed., CRC Press, Boca Raton, Florida.

[23] Belhachat, D., Mekimene, L., Belhachat, M., Ferradji, A., and Aid, F., 2018, Application of response surface methodology to optimize the extraction of essential oil from ripe berries of Pistacia lentiscus using ultrasonic pretreatment, J. Appl. Res. Med. Aromat. Plants, 9, 132-140.

[24] Maran, J.P., Manikandan, S., Vigna Nivetha, C., and Dinesh, R., 2017, Ultrasound assisted extraction of bioactive compounds from Nephelium lappaceum L. fruit peel using central composite face centered response surface design, Arabian J. Chem., 10, S1145-S1157.

[25] Mason, R.L., Gunst, R.F., and Hess, J.L., 2003, Statistical Design and Analysis of Experiments, with Applications to Engineering and Science, $2^{\text {nd }}$ Ed., Wiley-Interscience, New Jersey.

[26] Ameer, K., Shahbaz, H.M., and Kwon, J.H., 2017, Green extraction methods for polyphenols from plant matrices and their byproducts: A review, Compr. Rev. Food Sci. Food Saf., 16 (2), 295-315.

[27] Singh, N., Shrivastava, P., and Shah, M., 2014, Microwave-assisted extraction of lemongrass essential oil: Study of the influence of extraction method and process parameters on extraction process, J. Chem. Pharm. Res., 6 (11), 385-389.

[28] Liu, B., Fu, J., Zhu, Y., and Chen, P., 2018, Optimization of microwave-assisted extraction of essential oil from lavender using response surface methodology, J. Oleo Sci., 67 (10), 1327-1337.

[29] Tran, T., Nguyen, H., Nguyen, D., Nguyen, T., Tan, H., Nhan, L., Nguyen, D., Tran, L., Do, S., and Nguyen, T., 2018, Optimization of microwaveassisted extraction of essential oil from Vietnamese basil (Ocimum basilicum L.) using response surface methodology, Processes, 6 (11), 206.

[30] Ballard, T.S., Mallikarjunan, P., Zhou, K., and O'Keefe, S., 2010, Microwave-assisted extraction of phenolic antioxidant compounds from peanut skins, Food Chem., 120 (4), 1185-1192.

[31] Rostagno, M.A., and Prado, J.M., 2013, Natural Product Extraction: Principles and Applications, Royal Society of Chemistry, Cambridge.

[32] Desai, M.A., and Parikh, J., 2012, Microwave assisted extraction of essential oil from Cymbopogon flexuosus (steud.) Wats.: A parametric and comparative study, Sep. Sci. Technol., 47 (13), 1963-1970. 
[33] Alara, O.R., Abdurahman, N.H., Ukaegbu, C.I., and Azhari, N.H., 2018, Vernonia cinerea leaves as the source of phenolic compounds, antioxidants, and anti-diabetic activity using microwave-assisted extraction technique, Ind. Crops Prod., 122, 533-544.

[34] Guenther, E., 1950, The Essential Oils: Vol. 4: Individual Essential Oils of the Plant Families Gramineae, Lauraceae, Burseraceae, Myrtaceae, Umbelliferae and Geraniaceae, D. Van Nostrand Company, Inc., New York.

[35] Gaylor, R., Michel, J., Thierry, D., Panja, R., Fanja, F., and Pascal, D., 2014, Bud, leaf and stem essential oil composition of Syzygium aromaticum from Madagascar, Indonesia and Zanzibar, Int. J. Basic Appl. Sci., 3 (3), 224-233.

[36] Boughendjioua, H., 2018, Essential oil composition of Syzygium aromaticum (L.), Int. Res. J. Pharm. Med. Sci., 1 (3), 26-28.

[37] Kennouche, A., Benkaci-Ali, F., Scholl, G., and Eppe, G., 2015, Chemical composition and antimicrobial activity of the essential oil of Eugenia caryophyllata cloves extracted by conventional and microwave techniques, J. Biol. Act. Prod. Nat., 5 (1), 1-11.

[38] Golmakani, M.T., Zare, M., and Razzaghi, S., 2017, Eugenol enrichment of clove bud essential oil using different microwave-assisted distillation methods, Food Sci. Technol. Res., 23 (3), 385-394.

[39] Wang, F., Teng, Z., Liu, D., Wang, Y., Lou, J., and Dong, Z., 2020, $\beta$-Caryophyllene liposomes attenuate neurovascular unit damage after subarachnoid hemorrhage in rats, Neurochem. Res., 45 (8), 17581768.

[40] Sköld, M., Karlberg, A.T., Matura, M., and Börje, A., 2006, The fragrance chemical $\beta$-caryophyllene Air oxidation and skin sensitization, Food Chem. Toxicol., 44 (4), 538-545.

[41] Sałata, A., Buczkowska, H., and NurzyńskaWierdak, R., 2020, Yield, essential oil content, and quality performance of Lavandula angustifolia leaves, as affected by supplementary irrigation and drying methods, Agriculture, 10 (12), 590.

[42] Safrudin, I., Maimulyanti, A., and Prihadi, A.R., 2015, Effect of crushing of clove bud (Syzygium aromaticum) and distillation rate on main constituents of the essential oil, Am. J. Essent. Oils Nat. Prod., 2 (3), 12-15.

[43] Hastuti, L.T., Saepudin, E., Cahyana, A.H., Rahayu, D.U.C., Murni, V.W., and Haib, J., 2017, The influence of sun drying process and prolonged storage on composition of essential oil from clove buds (Syzygium aromaticum), AIP Conf. Proc., 1862, 030092.

[44] Tran, T.H., Nguyen, D.C., Phu, T.N.N., Ho, V.T.T., Vo, D.V.N., Bach, L.G., and Nguyen, T.D., 2019, Research on lemongrass oil extraction technology (hydro-distillation, microwave-assisted hydrodistillation), Indones. J. Chem., 19 (4), 1000-1007. 